\title{
Identification and Characterization of a Novel Recurrent ERCC6 Variant in Patients with a Severe Form of Cockayne Syndrome B
}

\author{
Khouloud Zayoud ${ }^{1,2}$, Ichraf Kraoua ${ }^{3}$, Asma Chikhaoui ${ }^{1}$, Nadège Calmels ${ }^{4,5}$, Sami Bouchoucha ${ }^{6}$, \\ Cathy Obringer ${ }^{5}$, Clément Crochemore $^{7}$, Dorra Najjar ${ }^{1}$, Sinda Zarrouk ${ }^{8}$, Najoua Miladi $^{9}$, Vincent Laugel ${ }^{5}$, \\ Miria Ricchetti ${ }^{7}$, Ilhem Turki ${ }^{3}$ and Houda Yacoub-Youssef ${ }^{1, * \text { (D) }}$ \\ 1 Laboratory of Biomedical Genomics and Oncogenetics (LR16IPT05), Institut Pasteur de Tunis, \\ Université Tunis El Manar, El Manar I, Tunis 1002, Tunisia; zayoudkhouloud@gmail.com (K.Z.); \\ asma.lfsv@gmail.com (A.C.); dorra.najjar2@gmail.com (D.N.) \\ 2 Faculté des Sciences de Bizerte, Bizerte 7000, Tunisia \\ 3 LR18SP04 and Department of Child and Adolescent Neurology, National Institute Mongi Ben Hmida of \\ Neurology, Tunis 1007, Tunisia; kraoua_ichraf@yahoo.fr (I.K.); ilhem.benyoussef58@gmail.com (I.T.) \\ 4 Laboratoires de Diagnostic Génétique, Institut de Génétique Médicale d'Alsace, Nouvel Hôpital Civil, \\ Hôpitaux Universitaires de Strasbourg, 67000 Strasbourg, France; nadege.calmels@chrustrasbourg.fr \\ 5 Laboratoire de Génétique Médicale, INSERM U1112, Institut de génétique médicale d'Alsace, CRBS, \\ 67000 Strasbourg, France; obringercathy@gmail.com (C.O.); Vincent.LAUGEL@chru-strasbourg.fr (V.L.) \\ 6 Service Orthopédie, Hôpital d'enfant Béchir Hamza, Tunis 1000, Tunisia; sami.bouchoucha@yahoo.com \\ 7 Institut Pasteur, Team Stability of Nuclear and Mitochondrial DNA, Stem Cells and Development, \\ UMR 3738 CNRS, 25-28 rue du Dr. Roux, 75015 Paris, France; clement.crochemore@pasteur.fr (C.C.); \\ miria.ricchetti@pasteur.fr (M.R.) \\ check for \\ updates \\ Citation: Zayoud, K.; Kraoua, I.; \\ Chikhaoui, A.; Calmels, N.; \\ 8 Genomics Platform, Institut Pasteur de Tunis (IPT), Tunis-Belvédère, Tunis 1002, Tunisia; \\ sinda.zarrouk@pasteur.tn \\ 9 Maghreb Medical Center, El Manar III, Tunis 9000, Tunisia; Najoua.miladi@hotmail.fr \\ * Correspondence: houda.yacoub@pasteur.utm.tn
} Bouchoucha, S.; Obringer, C.; Crochemore, C.; Najjar, D.; Zarrouk, S.; Miladi, N.; et al. Identification and Characterization of a Novel Recurrent ERCC6 Variant in Patients with a Severe Form of Cockayne Syndrome B. Genes 2021, 12, 1922. https:// doi.org/10.3390/genes12121922

Academic Editor: Garth D. Ehrlich

Received: 10 November 2021 Accepted: 25 November 2021 Published: 29 November 2021

Publisher's Note: MDPI stays neutral with regard to jurisdictional claims in published maps and institutional affiliations.

Copyright: (c) 2021 by the authors. Licensee MDPI, Basel, Switzerland. This article is an open access article distributed under the terms and conditions of the Creative Commons Attribution (CC BY) license (https:// creativecommons.org/licenses/by/ $4.0 /)$.
Abstract: Cockayne syndrome (CS) is a rare disease caused by mutations in ERCC6/CSB or ERCC8/ $C S A$. We report here the clinical, genetic, and functional analyses of three unrelated patients mutated in ERCC6/CSB with a severe phenotype. After clinical examination, two patients were investigated via next generation sequencing, targeting seventeen Nucleotide Excision Repair (NER) genes. All three patients harbored a novel, c.3156dup, homozygous mutation located in exon 18 of ERCC6/CSB that affects the $\mathrm{C}$-terminal region of the protein. Sanger sequencing confirmed the mutation and the parental segregation in the three families, and Western blots showed a lack of the full-length protein. NER functional impairment was shown by reduced recovery of RNA synthesis with proficient unscheduled DNA synthesis after UV-C radiations in patient-derived fibroblasts. Despite sharing the same mutation, the clinical spectrum was heterogeneous among the three patients, and only two patients displayed clinical photosensitivity. This novel ERCC6 variant in Tunisian patients suggests a founder effect and has implications for setting-up prenatal diagnosis/genetic counselling in North Africa, where this disease is largely undiagnosed. This study reveals one of the rare cases of CS clinical heterogeneity despite the same mutation. Moreover, the occurrence of an identical homozygous mutation, which either results in clinical photosensitivity or does not, strongly suggests that this classic CS symptom relies on multiple factors.

Keywords: Cockayne syndrome; ERCC6; accelerated aging; neurodegeneration; DNA repair disorder

\section{Introduction}

Cockayne syndrome (CS) is a rare autosomal recessive disorder. It is a progressively devastating disease, which displays multiorgan dysfunction. CS is mainly characterized by psychomotor retardation, cerebral atrophy, microcephaly, mental retardation, sensorineural hearing loss, and premature aging, along with other defects such as cutaneous photosensitivity, kyphosis, ankylosis, and optic atrophy. In 2010, a study highlighted a broad clinical 
spectrum of 84 cases of CS patients and defined major diagnostic criteria such as microcephaly, as well as minor diagnostic criteria such as photosensitivity [1]. However, these criteria are neither precocious nor specific to CS [2,3]. In fact, most signs and symptoms in CS patients, such as cerebral atrophy, are also found in mitochondrial diseases $[4,5]$. To complicate the situation, the reported clinical and mutation spectrum of CS keeps expanding $[2,6,7]$.

CS belongs to the family of pathologies related to the NER pathway. NER removes UVs and chemically induced DNA lesions. It includes two distinct sub-pathways: the global genome NER (GG-NER) sub-pathway, a system which prevents mutagenesis by probing the whole genome, and the transcription-coupled NER (TC-NER) which removes transcription-blocking lesions to permit gene expression [8]. Deficiencies in NER proteins can cause a variety of diseases, ranging from ultraviolet radiation-sensitive syndrome (UVSS), to cancer predisposing Xeroderma pigmentosum (XP), to Trichothiodystrophy (TTD), to a severe premature aging disease such as CS.

In Europe, the incidence of CS is estimated to be 1 case per 200,000 births [9]. Although the incidence rates of other DNA repair disorders, such as XP have been reported in Tunisia [10], no epidemiological data are available for CS.

To date, genetic investigations have shown that $\mathrm{CS}$ is essentially assigned to mutations in two genes of the TC-NER pathway: ERCC6 (CSB, OMIM 609413) (NM_000124) and ERCC8 (CSA, OMIM 609412) (NM_000082.3). Deep clinical and molecular analyses in a large cohort of patients revealed that phenotype/genotype correlation is difficult to establish, even with a huge heterogeneity among CS patients (including siblings) [1,11-14]. The most severe cases, CS type II, most often occur due to CSB mutations [15], whereas CSA mutations are generally associated with the milder form, CS type I [6]. However, this association is not always straightforward, for instance the mild form can also be due to CSB mutations. Of note, clinical photosensitivity is detected in only a fraction of patients, displaying a variety of mutations, and is essentially uncoupled from the severity of the disease $[2,16]$.

The phenotypic variability represents, therefore, a challenge for establishing a diagnosis and supportive treatment, plus patients exhibit a short life span (generally less than 5 years for the severe forms, and 16 years for the moderate phenotypes) [17]. Hence, next generation sequencing technologies are of particular interest for molecular diagnosis of such cases [18].

To date, approximately $65 \%$ of CS patients have been linked to mutations in ERCC6 and 35\% to mutation in ERCC8 [15]. Interestingly, CS patients in Tunisia and other Arab countries carry mutations predominantly in ERCC8. Several studies have suggested that the relatively larger proportion of ERCC8 defects in these areas is attributed to founder effects amplified by high frequencies of consanguineous unions [1,2]. For instance, a high carrier frequency of the p.Tyr322* CS-disease-causing variation in ERCC8 was reported among Christian Arabs in northern Israel, which is considered as an ancient founder mutation that may have originated in the Christian Lebanese community [19].

To date, seventeen CS patients have been reported in the Tunisian population: two siblings with an independent mutation (c.400-2A $>$ G) in ERCC8/CSA [20] and two other siblings with the recurrent mutation (c.598_600delins) ERCC8/CSA [21]. Five more CS patients have been clinically and biochemically characterized, but the mutation has not been identified [16,22]. Recently, we reported a detailed clinical characterization of eight CS-A patients. In that cohort, we showed that siblings carrying either the c. $843+1 \mathrm{G}>\mathrm{C}$ or the c. 598_600delinsAA mutations display remarkable phenotypic differences [23].

In the present study, we describe a novel ERCC6 mutation in three CS patients belonging to independent families that originate from northwestern Tunisia. The targeted gene sequencing showed a homozygous variation in all cases. We showed its deleterious effect on the CSB protein by Western blots and defective repair of UV-induced DNA damage in CS patient cells. 


\section{Materials and Methods}

\subsection{Patients}

Three patients were recruited from the Department of Child Neurology (National Institute Mongi Ben Hmida of Tunis) in 2018-2019, where they had undergone neurological and general examination routine since 2017. Blood tests, metabolic tests, and CT scans and/or brain MRIs and electrophysiological studies, as well as genetic tests, have been completed for these patients. After obtaining written informed consent from the families of the patients (as these CS patients were minors), blood, skin biopsies, and genealogical data were collected. The present study was conducted in accordance with Helsinki principles and approved by Institute Pasteur Ethics Committee in Tunisia under the ethical accord number (reference 2017/31/I/LR16IPT05/V2).

\subsection{DNA Extraction, Quantification, and Quality Control}

Genomic DNAs (gDNA) was isolated from whole blood samples of patients and their parents, using a FlexiGene kit (Qiagen) in accordance with the instructions of the manufacturer. DNA concentration and quality were assessed using a Nanodrop Spectrophotometer (Thermo Scientific, Wilmington, NC, USA). The required DNA concentration for NGS analysis was adjusted to $5 \mu \mathrm{g}$.

\section{3. gDNA Sequencing}

Genetic studies were started by screening for the recurrent ERCC8 pathogenic variation, already described in North African CS patients (NM_000082.3 c. 598_600delinsAA p.Tyr200Lysfs*12) using Sanger sequencing. ERCC8 exon 7 was amplified with the following primers set (F: 5' CCCTTTGAACTTATCACCTG $3^{\prime}$ R: 5' CCTCTGTGTCCCTAGCACAAT $3^{\prime}$ ) and sequenced using the ABI 3130 Genetic Analyzer (Applied Biosystems).

\subsubsection{Targeted Next Generation Sequencing}

In absence of the recurrent variation, molecular screening of two patients was continued by a next generation sequencing (NGS) assay, targeting 17 genes involved in the NER pathway (DDB2, ERCC1, ERCC2, ERCC3, ERCC4, ERCC5, ERCC6, ERCC8, GTF2H5, MPLKIP , PCNA, POLH, RNF113A, SMARCAL1, UVSSA, XPA, XPC) adapted from [18]. Regions of interest (exons and flanking intronic sequences) were captured using SureSelect QXT Agilent probes, and libraries were sequenced on a NextSeq550 Illumina platform. Single nucleotide variants (SNVs) and indels calling were performed with the Genome Analysis Toolkit v.3.4.46 with the help of an in-house pipeline (STARK, https: / / github.com/bioinfo-chru-strasbourg/STARK, accessed on 19 May 2019) and following the GATK best practice. Annotation and ranking of SNVs and indels were performed by VaRank [24]. Copy number variants (CNVs) were called using the CANOES program [25] and annotated with AnnotSV [26].

\subsubsection{Targeted Sanger Sequencing}

The polymerase chain reaction (PCR) was performed using primer pair covering exon 18 of ERCC6 (F: 5' CTGCAAGACCTGGGAGATT 3' R: 5' CAGGGTCTCTTTCAAAGGA $3^{\prime}$ ). PCR products were sequenced on automated ABI3130 (Applied Biosystems, Waltham, MA, USA) using the ABI Prism BigDye Terminator V3.1 Cycle Sequencing Kit.

\subsection{DNA Repair Assay in Primary Dermal Fibroblasts}

Dermal fibroblasts were obtained from skin biopsies of two patients (CS10 and CS14). Cells were grown at $37^{\circ} \mathrm{C}$ in $5 \% \mathrm{CO}_{2}$ humidified atmosphere in Dulbecco's Modified Eagle Medium (DMEM) (1 g/L glucose) with GLUTAMAX (Life Technologies (Gibco) supplemented with $10 \%$ of fetal calf serum (Gibco) and 1\% penicillin/streptomycin (Gibco). All primary fibroblast cultures were assessed at the same passage number, PN (PN 3 to 4 ). The activity of the NER system following UV irradiations was measured via unscheduled DNA 
synthesis (UDS) and recovery of RNA synthesis (RRS) after DNA damaging. These two assays are standard tests for the clinical diagnosis of DNA repair-related diseases [27-29].

Briefly, fibroblasts were plated on coverslips in 6-well plates and exposed to UV-C doses at $0,5,10$, and $15 \mathrm{~J} / \mathrm{m}^{2}$. DNA de novo synthesis was evaluated via the incorporation of 5-ethynyl-2'-deoxyuridine (5-EdU) in CS10 and CS14 patient cells, in a healthy donor (negative control), and in an XPF and a CS donor (positive controls). Similarly, and, after $24 \mathrm{~h}$, primary fibroblasts irradiated with UV-C doses $\left(0,6,12\right.$, and $\left.20 \mathrm{~J} / \mathrm{m}^{2}\right)$, underwent the RRS assay. The RNA synthesis was performed by evaluating the incorporation of 5-ethynyl uridine (5-EU). The images were analyzed with Image J for 50 randomly selected cells, originating from three independent experiments, and the average nuclear fluorescence intensity was calculated.

\subsection{Western Blotting}

Cells in culture were pelleted and lysed with lysis buffer $(50 \mathrm{mM}$ Tris- $\mathrm{HCl} \mathrm{pH} 7.5$, $150 \mathrm{mM} \mathrm{NaCl}, 1 \%$ Triton X-100, 0.1\% SDS, $1 \mathrm{mM}$ EDTA), and protease/phosphatase inhibitor mixture (Roche, Basel, Switzerland)). Lysed cells were not centrifuged, and the whole extract was subjected to sonication (Bioruptor, Diagenode, Liège, Belgium). The protein content was determined with the Bradford assay, and $15 \mu \mathrm{g}$ of protein were boiled in the presence of Laemmli Sample Buffer (\#161-0737, Bio-Rad, Hercules, CA, USA) containing 2.5\% of 2-mercaptoethanol (\#M3148, Sigma-Aldrich, St. Louis, MO, USA) at $95^{\circ} \mathrm{C}$ for $5 \mathrm{~min}$, run for SDS-PAGE (4-15\% Mini-PROTEAN TGX gel, \#4568083, Bio-Rad, Hercules, CA, USA), and transferred onto a nitrocellulose transfer membrane (Trans-Blot Turbo, \#1704158, Bio-Rad, Hercules, CA, USA).

The membrane was then blocked with $5 \%$ milk in phosphate buffer saline (PBS)- $0.1 \%$ Tween20 (\#P1379, Sigma-Aldrich, St. Louis, MO, USA) for $1 \mathrm{~h}$ at room temperature (RT) and probed with a specific primary antibody, either rabbit polyclonal $\alpha$-CSB (1:1000, \#ab96089, Abcam, Cambridge, UK) that recognizes aa 300-750 or rabbit polyclonal $\alpha-C S B(1: 2000$, \#A301-345A, Bethyl, Montgomery, TX, USA) that recognizes aa 1-50, overnight at $4{ }^{\circ} \mathrm{C}$. After five washes in PBS containing 0.1\% Tween20, the membrane was incubated with HRP-conjugated secondary antibody (1:10,000, Thermo Fisher Scientific, Waltham, MA, USA), as well as $\alpha$-GAPDH (1:5000,\#12004168, Bio-Rad, Hercules, CA, USA) human Fab fragments for $1 \mathrm{~h}$ at RT, revealed by chemiluminescence and fluorescence, respectively. Detection was performed using ChemiDoc MP Imaging System (Bio-Rad, Hercules, CA, USA). Staining with ATX Ponceau S Red (\#09189, Sigma-Aldrich, St. Louis, MO, USA) was used as a further marker of protein content. Uncropped and unprocessed scans of all the blots can be provided upon request.

\section{Results}

\subsection{Clinical Features of CS-B Patients}

Clinical, imaging, and genetic characterization of the three patients are summarized in Table 1.

Table 1. Clinical, biological, imaging, and genetic findings of patients with the novel CSB variant.

\begin{tabular}{cccc}
\hline Family & CS10 & CS12 & CD14 \\
Sex & M & F & M \\
Reference sequence & NM_000124.3 & NM_000124.3 & NM_000124.3 \\
c.3156dup & c.3156dup \\
Homozygous ERCC6 mutation & p.(Arg1053Thr*8) & p.(Arg1053Thr8) & p.(Arg1053Thr*8) \\
Protein modification & Northwest & Northwest & Northwest \\
\hline Geographic origin & Consanguineous & Consanguineous & Consanguineous \\
\hline Consanguinity/Endogamy & $2-5$ & 6-8 & 6-8 \\
Range age at diagnosis (years) & Birth & Birth & G months \\
Age at first symptoms(months) & Growth delay & Growth delay & Psychomotor delay \\
First symptoms & & &
\end{tabular}


Table 1. Cont.

\begin{tabular}{|c|c|c|c|}
\hline Family & CS10 & CS12 & CD14 \\
\hline \multicolumn{4}{|l|}{ Prenatal abnormalities } \\
\hline IUGR & NA & NA & NA \\
\hline Microcephaly & + & + & + \\
\hline Cerebellar hypoplasia & NA & NA & NA \\
\hline Oligoamnios & NA & NA & NA \\
\hline \multicolumn{4}{|l|}{ Birth findings } \\
\hline Birth weight (g) & 2550 & 2300 & 2950 \\
\hline Birth height $(\mathrm{cm})$ & 45 & 45 & 48 \\
\hline Head circumference at birth (cm) & 33 & 32 & 32 \\
\hline Postnatally findings (years) & $2-5$ & $6-8$ & -8 \\
\hline Weight $(\mathrm{kg})$ & $6(-3 \mathrm{SD})$ & $8(-4 \mathrm{SD})$ & $8(-3 \mathrm{SD})$ \\
\hline Height $(\mathrm{cm})$ & $70(-2 \mathrm{SD})$ & $82(-6 \mathrm{SD})$ & $76(-3 \mathrm{SD})$ \\
\hline Head circumference $(\mathrm{cm})$ & $41(-2 \mathrm{SD})$ & $40(-8.5 \mathrm{SD})$ & $42(-3 \mathrm{SD})$ \\
\hline \multicolumn{4}{|l|}{ Dysmorphism } \\
\hline Enophtalmia & + & + & + \\
\hline Thin skin & - & + & + \\
\hline Bird-like nose & + & + & + \\
\hline \multicolumn{4}{|l|}{ Neurological findings } \\
\hline Microcephaly & + & + & + \\
\hline Psychomotor delay & + & + & + \\
\hline Independent sitting (months) & 8 & 5 & Not acquired \\
\hline Independent walking (years) & 1.5 & 4 & Not acquired \\
\hline Mental retardation & + & + & + \\
\hline Limb spasticity & + & + & + \\
\hline Retractions & - & + & + \\
\hline Pyramidal signs & + & + & + \\
\hline Neurogenic signs & - & + & + \\
\hline Ataxia & + & + & - \\
\hline Extrapyramidal signs & - & - & - \\
\hline Epilepsy & - & - & - \\
\hline Behavioral abnormalities & - & - & - \\
\hline Ophthalmological findings & + & - & - \\
\hline Cataract & - & - & + \\
\hline Optic atrophy & - & + & - \\
\hline \multicolumn{4}{|l|}{ Pigmentary retinopathy } \\
\hline \multicolumn{4}{|l|}{ Otolaryngological findings } \\
\hline Sensorineural deafness & + & + & + \\
\hline Auditory evoked response & $60 / 70 \mathrm{~dB}$ & $\begin{array}{l}60 \mathrm{~dB} \text { (right ear)/no } \\
\text { response for the left ear }\end{array}$ & NA \\
\hline \multicolumn{4}{|l|}{ Dermatological findings } \\
\hline Photosensitivity & + & + & - \\
\hline Eczema & - & - & - \\
\hline Thin skin & - & + & - \\
\hline Pigmentation abnormalities & - & - & + \\
\hline Hair abnormalities & - & - & - \\
\hline Nail abnormalities & - & - & - \\
\hline \multicolumn{4}{|l|}{ Dental abnormalities } \\
\hline Caries & + & + & + \\
\hline Tooth enamel abnormalities & - & + & + \\
\hline Morphological teeth abnormalities & - & + & + \\
\hline \multicolumn{4}{|l|}{ Laboratory findings } \\
\hline AST $(\mathrm{NV}<40 \mathrm{U} / \mathrm{L})$ & 65 & 108 & 45 \\
\hline ALT $(\mathrm{NV}<40 \mathrm{U} / \mathrm{L})$ & 77 & 180 & 80 \\
\hline Creatinine (NV50-110 $\mu \mathrm{mol} / \mathrm{L})$ & 22 & 20 & 31 \\
\hline
\end{tabular}


Table 1. Cont.

\begin{tabular}{|c|c|c|c|}
\hline Family & CS10 & CS12 & CD14 \\
\hline \multicolumn{4}{|l|}{ Imaging findings } \\
\hline Calcifications & + & + & + \\
\hline Hypomyelination & + & - & + \\
\hline Cerebellar atrophy & + & + & + \\
\hline Brainstem atrophy & + & + & + \\
\hline Nerve conduction velocities & NA & $\begin{array}{l}\text { (SPE. D) } 23.5 \mathrm{~m} / \mathrm{s} \\
\text { slowed }\end{array}$ & (SPE. D) $16 \mathrm{~m} / \mathrm{s}$ slowed \\
\hline Neurophysiological findings (ENMG Test) & NA & $\begin{array}{l}\text { Sensory and motor } \\
\text { demyelinating } \\
\text { polyneuropathy }\end{array}$ & $\begin{array}{l}\text { Sensory and motor } \\
\text { demyelinating } \\
\text { polyneuropathy }\end{array}$ \\
\hline Others Findings & $\begin{array}{l}\text { Cryptorchidia, } \\
\text { toxoplasmosis during } \\
\text { pregnancy }\end{array}$ & - & $\begin{array}{l}\text { Cryptorchidia, } \\
\text { kyphosis }\end{array}$ \\
\hline
\end{tabular}

\subsubsection{General Presentation of the Patients}

This cohort includes two males (CS10 and CS14, aged 2 and 6 years, respectively) and one female (CS12, aged 7 years) from three unrelated Tunisian families. All patients were born from first-degree consanguineous parents, who originated from northwestern Tunisia (Figure 1).

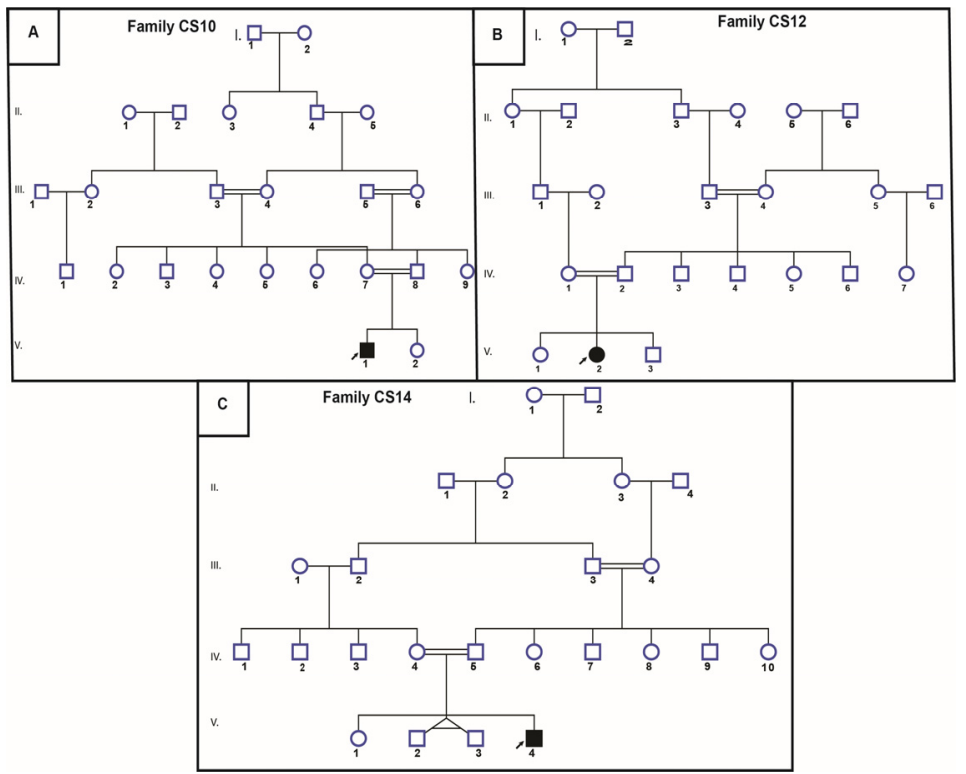

Figure 1. Pedigree of three unrelated Tunisian families. (A) pedigree of the CS10 family (B) pedigree of the CS12 family (C) pedigree of the CS14 family. The studied proband is indicated with an arrow.

\subsubsection{Pre- and Post-Natal Abnormalities}

The reported patients were born at term. Prenatal microcephaly was detected in all three patients through ultrasound screening (Table 1). Postnatally, birth weight was within the normal low range for all patients (mean birth weight of CS patients was $2600 \mathrm{~g}$, ranging from $2300 \mathrm{~g}$ to $2950 \mathrm{~g}$ ); birth height was also normal, whereas the head circumference values were under the normal range (mean head circumference of CS patients was $32.3 \mathrm{~cm}$, with the normal average of the head circumference of a newborn estimated as $35 \mathrm{~cm}$ ). All three patients developed severe growth failure and microcephaly (mean weight -7 SD, mean head circumference - 7.3 SD) (Table 1, and Supplementary Figure S1). 
3.1.3. Behavioral Abnormalities, and Muscular, Neurological, and Neurosensory Problems

All patients arrived in our department for examination displaying a psychomotor delay. Two patients (CS10 and CS12) were able to sit independently at a mean age of 6.5 months, whereas CS14 was unable to do so. Independent walking was acquired late for two patients (CS10 and CS12, at the age of 1.5 and 4 years, respectively) whereas patient CS14 could not walk independently.

As a general observation, the three patients had no language skills. However, they were interactive. Behavioral disturbances due to irritability and sleep disorders were not reported. Neurological examination showed a spasticity of limbs with predominance in lower limbs in all patients, leading to a progressive flexion retraction and neurological abnormalities in two patients (CS12 and CS14). Ataxia was observed in two cases (CS10 and CS12) and a kyphosis in patient CS14. No patient developed extrapyramidal symptoms.

Sensorineural deafness was detected in all cases. Ophthalmological examination revealed bilateral cataract for CS10, who underwent eye surgery at the age of 8 months. Pigmentary retinopathy was observed in the CS12 patient and optic atrophy in the CS14 patient (the most severe case). We also reported cryptorchidism in CS10 and CS14 (Table 1).

\subsubsection{Facial, Dental, and Skin Anomalies}

All patients displayed the typical CS appearance, with enophtalmia, large ears, thin skin, and a bird-like nose. In addition, teeth caries were reported in all patients, and anomalies in tooth shape, size, and number were reported in CS12 and CS14 (CS10 was too young for assessing these parameters).

Clinical photosensitivity was observed in CS10 and CS12, whereas pigmentation abnormalities were observed in patient CS14 (Table 1).

\subsubsection{Laboratory Investigations}

The biochemical analysis of AST / ALT showed hepatic cytolysis for all three patients, with the corresponding values of $65 / 77$ for patient CS10 at the age of 2 years, 108/180 for patient CS12 at the age of 7 years, and 45/80 for patient CS14 at the age of 8 years (Table 1). A mild serum creatinine decrease was also noted in all cases (CS10: $22 \mu \mathrm{mol} / \mathrm{L}$; CS12: $20 \mu \mathrm{mol} / \mathrm{L}$; CS14: $31 \mu \mathrm{mol} / \mathrm{L}$ ), compared to healthy controls (mean secretion level: $80 \mu \mathrm{mol} / \mathrm{L}$ ranging from $50 \mu \mathrm{mol} / \mathrm{L}$ to $110 \mu \mathrm{mol} / \mathrm{L})$.

\subsubsection{Neuroimaging Analysis}

Magnetic resonance imaging (MRI) showed hypomyelination in two patients (CS10, CS14) but not in CS12 (Figure 2).

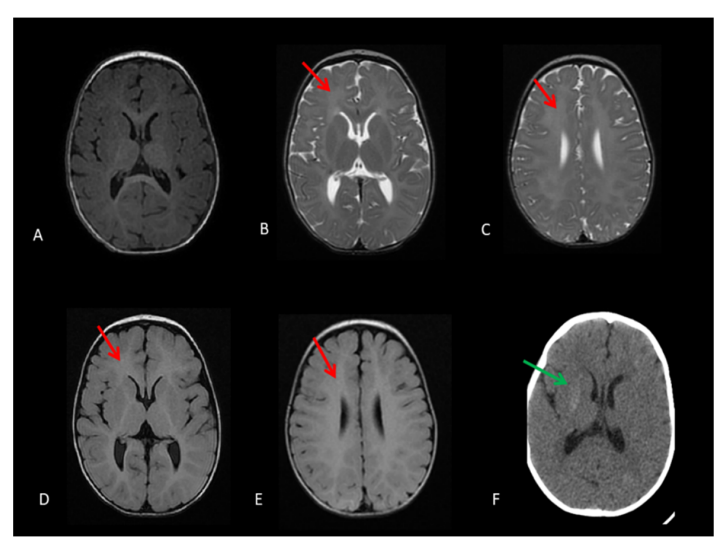

Figure 2. MRI images of patient CS10. (A) Axial T1-weighted image, (B,C) axial T2-weighted images, and (D,E) axial FLAIR-weighted images, showing isointensity of periventricular white matter on T1 and hyperintensity on T2. FLAIR suggestive of hypomyelinating leukodystrophy (red arrows). (F) CT scan shows lenticular calcifications (green arrow). 
Cerebellar atrophy and brainstem atrophy were observed in all cases. Two out of three patients (CS10, CS14) showed the full table of the features of neurological impairment, typical of CS (Table 1$)$.

\subsubsection{Neurophysiological Studies}

Electroneuromyography (ENMG) was performed in two patients (CS12 and CS14). Results were compatible with a sensory-motor polyneuropathy of a demyelinating mechanism [30]. Nerve conduction velocities were studied in two patients (CS12 and CS14), resulting in slow values in both cases $(23.5 \mathrm{~m} / \mathrm{s}$ and $16 \mathrm{~m} / \mathrm{s}$, respectively) (Table 1$)$.

\subsection{Genetic and Biochemical Analyses}

\subsubsection{Sanger Sequencing for Recurrent Mutations}

Clinical presentation of the three patients (CS10, CS12 and CS14) suggested Cockayne syndrome diagnosis. Molecular investigations have been started by screening the recurrent ERCC8 mutation c.598_600delinsAA using targeted Sanger sequencing. Indeed, this frameshift variant, introducing a premature stop codon resulting in a truncated protein, has been previously described in seven Tunisian families [21]. This variant was not found in the patients, and, therefore, samples from two patients underwent targeted gene sequencing covering exons of the 17 genes involved in the NER pathway.

3.2.2. Targeted Gene Sequencing Finding and Sanger Sequencing Validation for the Novel Variant

Targeted gene sequencing in two patients (CS10, CS14) identified a novel homozygous variation in exon 18 of the ERCC6 gene (NM_000124.3). The identified frameshift variation c.3156dup p. (Arg1053Thrfs*8) was then confirmed by Sanger sequencing in the three CS patients (Figure 3A, only patient CS12 is shown). The Sanger sequencing also confirmed the heterozygous carrier status of their respective parents (parents of CS10 and CS14, mother of CS12). This variation has been described only once at the heterozygous state in the gnomAD control database (allele frequency: 0.000003981). This variation causes a reading frameshift and a premature stop codon after eight codons. At the protein level, it could modify the protein sequence at p. (Arg1053Thrfs*8), resulting in a truncated protein (Figure 3B).

\subsection{Western Blot Validation of Protein Alteration}

Because of the insertion of a PGBD3 piggyBac transposon into ERCC6 intron 5, alternative splicing of the human ERCC6 gene results in the CSB full-length protein (1493 aa) as well as a CSB-PGBD3 fusion protein that joins the N-terminal CSB domain to the C-terminal PGBD3 transposase domain (1061 aa) [31]. Western blot analysis using a CSB antibody that targets aa 300-750, as well as an antibody that targets the N-terminal portion of the protein (aa 1-50), did not show the full-length protein in CS10 and CS14, whereas it was present in control fibroblasts from a healthy donor (Figure 4A,B). The truncated protein resulting from the mutation has an expected length of $1061 \mathrm{aa}$, and is, therefore, indistinguishable from the CSB PGBD3 fusion protein, also of 1061 aa in length (Figure 4C,D) 


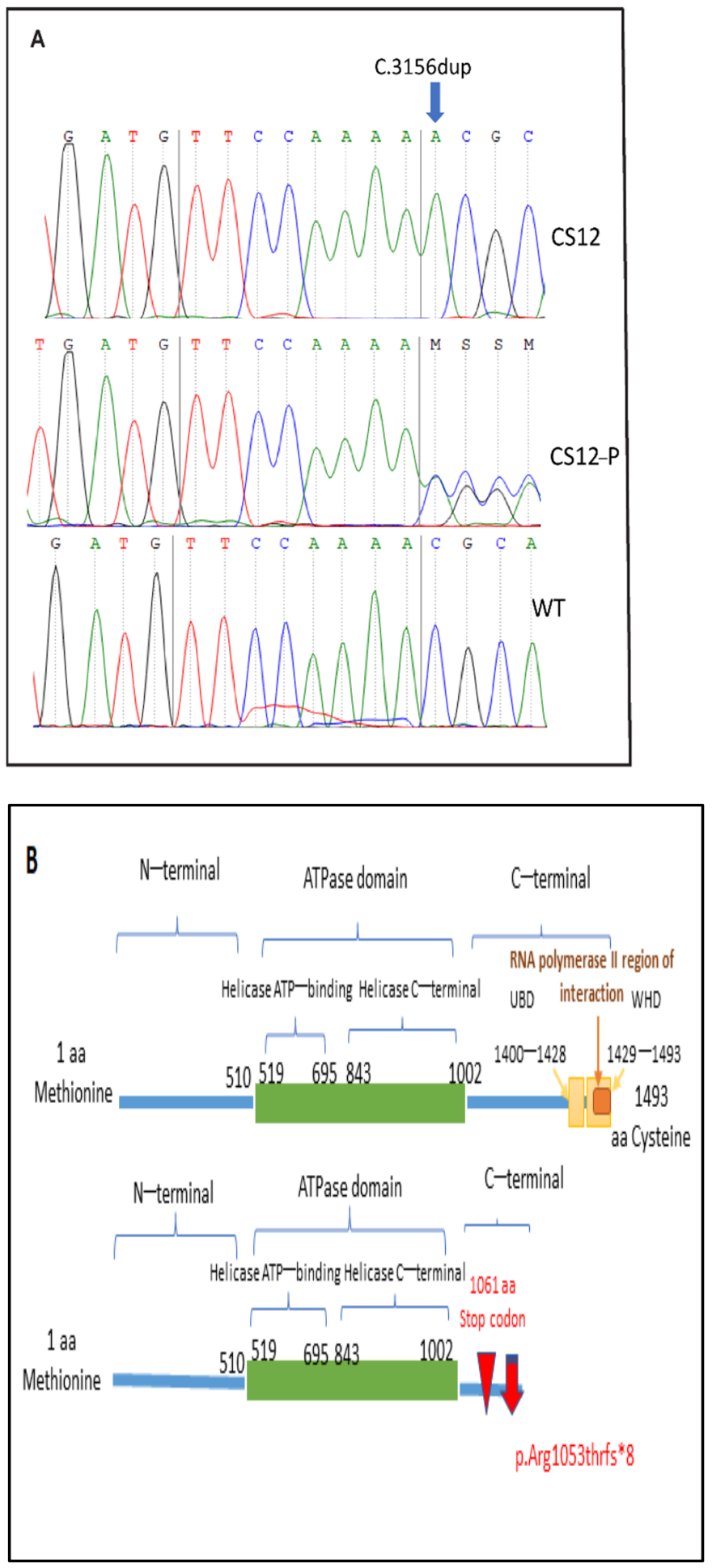

Figure 3. Genetic analysis. (A) Electropherogram showing the c.3156dup mutation at homozygous state in CS12, at a heterozygous state in the mother CS12-P, compared to a wild-type sample. (B) Schematic representation of the domains in the CSB protein (upper panel) and the novel variant (lower panel). The inverted red triangle represents the frameshift mutation and the red arrow the stop codon 8 aa downstream. 

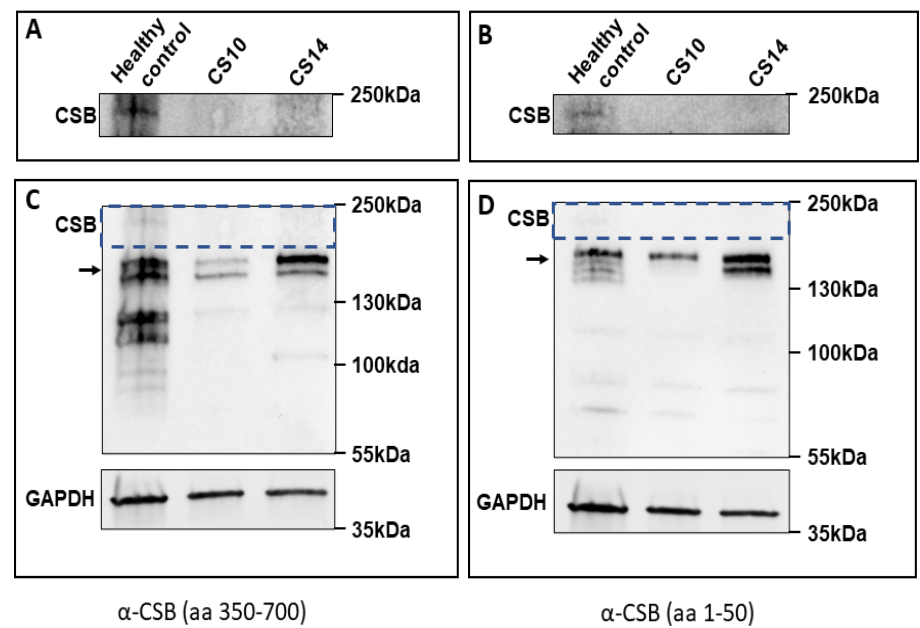

Figure 4. Western blot of CSB. (A,C) $\alpha$-CSB rabbit polyclonal Abcam. (B,D) $\alpha$-CSB rabbit polyclonal Bethyl. (A,B): the full-length form of the CSB protein is absent from CS10 and CS14 fibroblasts whereas it is present in a healthy control. (C,D): larger-sized Western blots at a lower exposure than in (A,B); arrows indicate the expected position of the CSB-piggyBac fusion protein (which is more abundant than the full-length CSB); hatched rectangles correspond to the part of the blot shown in $(\mathbf{A}, \mathbf{B})$. Lower panels: immunoblot of the loading control GAPDH.

\subsection{Cellular Response to UV in CS Patients}

UV radiation assays tested on fibroblasts derived from CS10 and CS14 patients showed reduced response to $\mathrm{UV}$, compared to healthy controls. The response to increasing doses $\left(0-15 \mathrm{~J} / \mathrm{m}^{2}\right)$ of UV-C radiation was first assessed by the RRS assay, which showed reduced RNA synthesis in CS10 and CS14 fibroblasts, compared to the healthy control. As expected for CS, unscheduled DNA synthesis UDS levels were normal in CS10 and CS14 fibroblasts. Altogether, these results indicate a defective capacity to repair UV-induced DNA damage on the transcribed strand in two CS patients, including CS14, who does not display clinical hypersensitivity to sunlight (Figure 5).

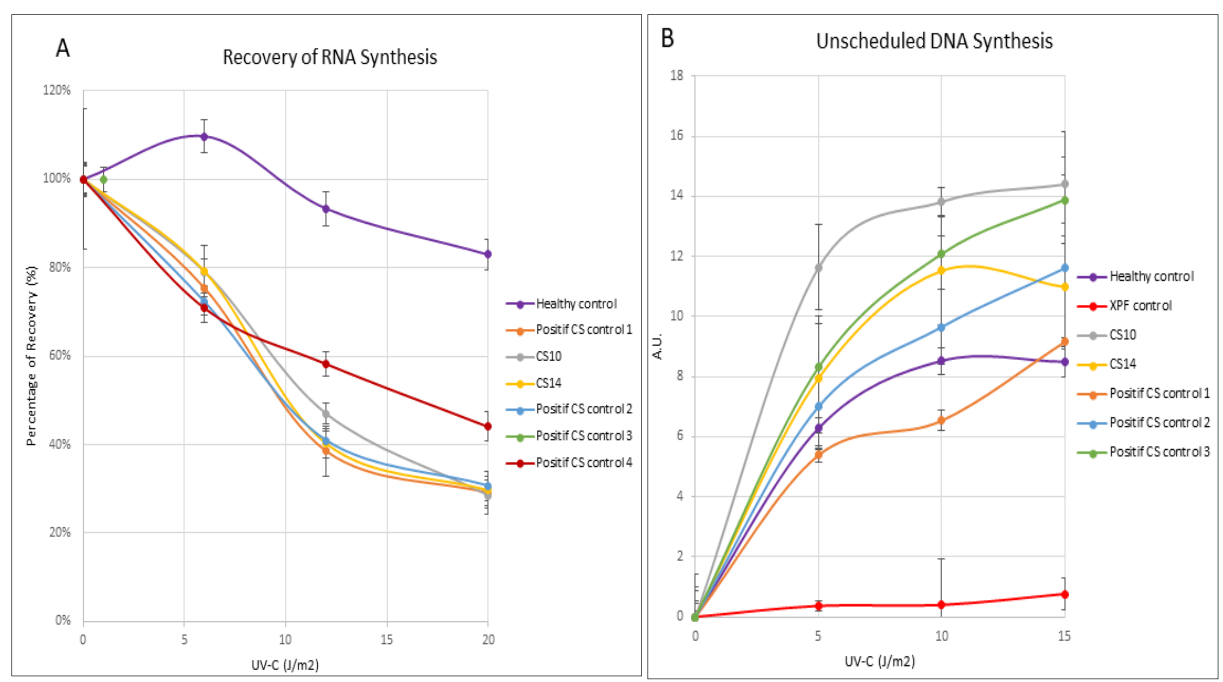

Figure 5. Response to UV radiation in fibroblasts. CS10 and CS14 fibroblasts compared to multiple CS, a XPF, and a healthy control. (A) RRS 24h after UV irradiation expressed in percentage of recovery after 5-EU incorporation, showing the defect of RNA Synthesis after UV exposure in CS fibroblasts. (B) UDS expressed in arbitrary units (a.u.) of 5-EdU fluorescence intensity. Differently from XP, CS patients show normal levels of unscheduled DNA synthesis. 


\section{Discussion}

\subsection{Common Mutation in Three CS Patients}

Cockayne syndrome is a rare autosomal recessive disorder, which is caused by a defect in proteins (CSA or CSB) that are notably involved in the DNA repair system TC-NER. CS, as a form of segmental progeria, recapitulates normal human aging in many of its aspects including cognitive dysfunction, high tone hearing loss, and cataracts [32]. Many autosomal recessive diseases are caused by consanguineous marriages. Due to traditional and cultural customs that incite consanguineous marriages ( $38 \%$ consanguinity), the Tunisian population displays a high frequency of autosomal recessive genetic transmitted pathologies [33]. Indeed, a recent study has identified more than 547 genetic diseases in Tunisia, $60 \%$ of which are due to recessive mutations in autosomal genes [34].

To date, 17 CS patients have been reported in the Tunisian population [2,16,20-22], and the majority of the reported cases (at least 12/17) display genetic defects in the ERCC8 gene. The relatively larger proportion of $E R C C 8$ defects in Tunisian patients can be attributed to a probable founder mutation c.598_600delinsAA carrier effect [23].

With this cohort we describe the first $E R C C 6 / C S B$ mutants in the Tunisian population. We reveal a novel frameshift variation c.3156dup, located in exon 18, within three unrelated families belonging to a close geographic area (in northwestern Tunisia). This occurrence suggests a common ancestor, and, therefore, a founder effect, since the three patients were born from first-degree consanguineous parents and exhibited close geographical distribution.

Further investigations, including haplotype analysis, are required to verify a founder mutation in this area.

\subsection{The Mutated CSB Protein}

The CSB protein has two major domains: a central ATPase domain, which is composed of an helicase ATP-binding domain spanning from amino acids 519 to 695, and an helicase C-terminal domain, which spans from amino acids 843 to 1002, flanked by N-terminal and C-terminal regions [35].

In addition to its involvement in the TC-NER pathway, the CSB protein, in synergy with CSA, is involved in other cellular processes. Several studies showed the implication of CSB and CSA in the control of p53 levels during genotoxic stress [36], ribosomal biogenesis, [37] proteostasis, cytokinesis [38], mitochondrial DNA repair, [39] and ATF3 degradation $[40,41]$. Moreover, recent data have shown that CSB plays a master role in replicative senescence of human fibroblasts by unmasking the $\mathrm{p} 21^{\text {waf1 }}$ promoter [42]. CSB is also thought to promote p21 degradation through ubiquitylation, due to its E3 ligase activity [43].

A further critical role of CSB C-terminal region in other aspects of the DNA repair process has been highlighted, namely, interaction with RNA polymerase II, translocation of the CSA protein to the nuclear matrix, and association of CSB with chromatin after UV irradiation [44-47].

In the present study, the frameshift variation p.(Arg1053Thrfs*8) was located within the C-terminal region of the CSB protein that interacts with RNA pol II, possibly altering CSB-related transcription. The insertion of an adenosine changed the reading frame and, thereby, the amino acid sequence of the CSB protein. A premature stop codon should then appear eight amino acids from the insertion site, causing the loss of three important regions englobing the $\mathrm{C}$-terminal region that likely contribute to the biological activity of this protein (Figure 3B). The loss of the TC-NER activity was confirmed by reduced RRS and unaffected UDS, upon UV irradiation in two patients, as in standard experiments that demonstrate CSB impairment. 


\subsection{Remarkable Clinical Features and Presence or Absence of Clinical Photosensitivity}

The clinical features of CSB patients in the cohort described here tend to be more severe than those reported in North Africa and Middle East, who displayed predominantly mutations in ERCC8/CSA.

Patients in this study were born at term with weight within the low normal range, but showed microcephaly at birth and postnatally. Of note, postnatal height and weight in these patients were lower than those reported in patients with CSA mutations at comparable ages and in the same geographical area. For instance, the CS10 patient at 2 years weighted $6 \mathrm{~kg}$ and had a height of a $70 \mathrm{~cm}$, which are much lower values than the CS6EA2 patient (CSA mutation), namely a weight of $11 \mathrm{~kg}$ weight, and a height of $83 \mathrm{~cm}$ [23].

Although harboring the same mutation, patients in this study display distinct clinical features of particular interest: one out of three patients in this cohort was not clinically photosensitive. Previous studies reported distinct CS patients that do not present clinical photosensitivity, as in Tunisian, Turkish, Italian, and Moroccan populations, despite the cells of these patients being defective in TC-NER repair [2,16,48,49]. Due to these numerous cases, cutaneous photosensitivity has been classified and is maintained as a minor criterion in the diagnosis of CS. Indeed, several studies have investigated such photosensitivity. It appears in $47 \%$ to $76 \%$ of cases, with no significant difference between CS patients mutated in ERCC6 or ERCC8 [2,3]. As in the previous studies, patients with and without clinical photosensitivity (CS10 and CS14, respectively) displayed impaired RRS and unaffected UDS. These tests confirm that the UV-repair mechanism is indeed impaired in both patients. For this reason, RRS following UV damage remains a useful analysis to confirm the diagnosis and is complementary to genetic investigations.

Pairs of a photosensitive and a non-photosensitive CS patient sharing the same homozygous mutations have been described for the less severe form (type I) for ERCC6/CSB (CS22PV/CS28PV) [2] and in our previous study for ERCC8/CSA (CS11/CS16) [23] (Supplementary Table S1). Here, we describe one patient associated with the severe CS type II form without photosensitivity (CS14) and two cases (CS10 and CS12) associated with the CS type I form with photosensitivity. Altogether, these data support the notion that clinical photosensitivity requires additional components than the CSA or CSB mutation. This is probably also the case for other highly heterogeneous CS clinical defects.

\subsection{Severe Characteristics of the Tunisian CSB Cohort}

This cohort displays a certain level of heterogeneity, beyond clinical photosensitivity. For instance, ataxia, cataract, thin skin, pigmentary retinopathy, contractures, neurogenic signs, and teeth abnormalities were alternatively present only in one out the three patients. More specifically, patient CS14 was characterized by severe neuromotor dysfunction, with psychomotor delay as first symptom (at 9 months), and failure to acquire independent sitting and walking capacities. This patient, however did not show ataxia. Patient CS14, who was not clinically photosensitive, displayed pigmentation abnormalities and neurological signs, plus was the only one in this cohort to suffer from optic atrophy.

Patients CS10 and CS12 displayed growth delay as a first symptom, but the former, differently from the latter, did not display contractures, neurological signs, pigmental retinopathy, dental abnormalities, or thin skin. Conversely, patient CS12 displayed neither hypomyelination (similarly to patients CS10 and CS14), nor cataracts (similarly to patient CS10).

All three CSB patients reported here suffered from lenticular calcifications, brain atrophy, and brainstem, while also showing decreased levels of creatinine in mild serum. A progressive decrease in serum creatinine was reported in the elderly and was suggestive of chronic kidney disease [50]. In addition, all these patients displayed sensory-motor polyneuropathy with a demyelinating mechanism, which involves severe symptoms. Moreover, hearing loss was detected in all reported patients (not shown). In fact, CS is typically associated with prominent sensorineural hearing loss, which is also a frequent age-related condition [37]. 
To date, neither the type of variation nor its position in the protein have been clearly associated with a specific clinical severity of CS, indicating that underlying mechanisms remain to be elucidated. This situation highlights the requirement of a complete clinical examination, accompanied by genetic analyses, to elucidate complex syndromes such as CS. Several studies have suggested the implication of other mechanisms that may explain specific features of the severe phenotypes, such as neurodegeneration observed in CS patients; for instance, defective transcription of ATF3 responsive genes upon genotoxic stress [41], or alteration of mitochondrial function due to mismanaged oxidative stress [50].

\section{Conclusions}

We identified here a novel homozygous CSB frameshift variation that enlarges the mutational and pathological spectra of CS. Patients with this mutation not only display very severe symptoms but also a remarkable level of clinical heterogeneity. In particular, they display (or not) clinical photosensitivity, indicating that this frequent CS defect requires additional factors than the CSB mutation to occur. We propose to add this variation to the molecular standard diagnosis of patient clinical features suggestive of CS phenotype, especially for patients originating from northwestern Tunisia and from the North African region.

Supplementary Materials: The following are available online at https:/ /www.mdpi.com/article/ 10.3390/genes12121922/s1, Supplementary Table S1. Presence or absence of clinical photosensitivity in CS patients with the same mutation. Supplementary Figure S1. Growth charts for CS-B patients (0-8 years), compared to the WHO reference charts (mean, 3rd, and 97th percentile). (A) Weight, (B) Height, and (C) Occipital frontal circumference (OFC).

Author Contributions: Experiments, data analysis and manuscript draft, K.Z.; clinical investigation of patients and family members, I.K.; cell culture help, pre-screening patients for known mutations and data analysis, A.C.; target gene sequencing experiments, data interpretation and critical manuscript revision, N.C.; skin biopsies, S.B.; fibroblasts expansion, UDS and RRS experiments, C.O.; WB analysis and CSB protein-modification interpretation help, C.C.; genetic investigation contributions, D.N., S.Z. and N.M.; critical analysis of the clinical findings of CS patients, V.L. and I.T.; study concept, design and critical manuscript revision, H.Y.-Y. and M.R.; study supervision, H.Y.-Y. All authors have read and agreed to the published version of the manuscript.

Funding: This work was supported by the Ministry of Higher Education and Scientific Research (LR20IPT /05), the "Programmes Transversaux de Recherche" project (PTR_Rejuvenage 2017-2019), the "Projet Collaboratif Interne (PCI_Ageing 2019_2021), the "MOBIDOC-753 (2017-2020) fellowship for PhD students, and the Agence Nationale de la Recherche (ANR) CS_AGE.

Institutional Review Board Statement: The study was approved by Institute Pasteur Ethics Committee in Tunisia (reference 2017/31/I/LR16IPT05/V2), in accordance with the Declaration of Hesinki Principles.

Informed Consent Statement: Written informed consent was obtained from the legal tutor of all patients for genetic investigation and publication.

Data Availability Statement: All processed data have been provided in the manuscript. Raw data, generated for this study could be provided by the corresponding author upon reasonable request.

Acknowledgments: The authors would like to thank the patients and their families for their collaboration. We thank Benjamin Montagne (Institut Pasteur, Paris) for the culturing and preparing fibroblasts for USD and RSS experiments.

Conflicts of Interest: The authors declare that they have no competing interest. 


\section{References}

1. Laugel, V.; Dalloz, C.; Durand, M.; Sauvanaud, F.; Kristensen, U.; Vincent, M.C.; Pasquier, L.; Odent, S.; Cormier-Daire, V.; Gener, B.; et al. Mutation update for the CSB/ERCC6 and CSA/ERCC8 genes involved in Cockayne syndrome. Hum. Mutat. 2010, 31, 113-126. [CrossRef] [PubMed]

2. Calmels, N.; Botta, E.; Jia, N.; Fawcett, H.; Nardo, T.; Nakazawa, Y.; Lanzafame, M.; Moriwaki, S.; Sugita, K.; Kubota, M.; et al. Functional and clinical relevance of novel mutations in a large cohort of patients with Cockayne syndrome. J. Med. Genet. 2018, 55, 329-343. [CrossRef]

3. Wilson, B.T.; Stark, Z.; Sutton, R.E.; Danda, S.; Ekbote, A.V.; Elsayed, S.M.; Gibson, L.; Goodship, J.A.; Jackson, A.P.; Keng, W.T.; et al. The Cockayne Syndrome Natural History (CoSyNH) study: Clinical findings in 102 individuals and recommendations for care. Genet. Med. 2016, 18, 483-493. [CrossRef]

4. Scheibye-Knudsen, M.; Croteau, D.L.; Bohr, V.A. Mitochondrial deficiency in Cockayne syndrome. Mech. Ageing Dev. 2013, 134, 275-283. [CrossRef] [PubMed]

5. Fisher, A.; Asghar, M.; Ryan, S.; Lynch, B.; Green, A.; Knerr, I. GP59 A rare cause of 'mitochondrial disorder': Cockayne syndrome. Arch. Dis. Child. 2019, 104, A53. [CrossRef]

6. Laugel, V. Cockayne syndrome: The expanding clinical and mutational spectrum. Mech. Ageing Dev. 2013, 134, 161-170. [CrossRef]

7. Narayanan, D.L.; Tuteja, M.; McIntyre, A.D.; Hegele, R.A.; Calmels, N.; Obringer, C.; Laugel, V.; Mandal, K.; Phadke, S.R. Clinical and Mutation Spectra of Cockayne Syndrome in India. Neurol. India 2021, 69, 362-366. [CrossRef] [PubMed]

8. Kciuk, M.; Marciniak, B.; Mojzych, M.; Kontek, R. Focus on UV-Induced DNA Damage and Repair-Disease Relevance and Protective Strategies. Int. J. Mol. Sci. 2020, 21, 7264. [CrossRef]

9. Pines, A.; Dijk, M.; Makowski, M.; Meulenbroek, E.M.; Vrouwe, M.G.; van der Weegen, Y.; Baltissen, M.; French, P.J.; van Royen, M.E.; Luijsterburg, M.S.; et al. TRiC controls transcription resumption after UV damage by regulating Cockayne syndrome protein A. Nat. Commun. 2018, 9, 1040. [CrossRef]

10. Zghal, M.; El-Fekih, N.; Fazaa, B.; Fredj, M.; Zhioua, R.; Mokhtar, I.; Mrabet, A.; Ferjani, M.; Gaigi, S.; Kamoun, M.R. Xeroderma pigmentosum. Cutaneous, ocular, and neurologic abnormalities in 49 Tunisian cases. La Tunis. Med. 2005, 83, 760-763.

11. Nance, M.A.; Berry, S.A. Cockayne syndrome: Review of 140 cases. Am. J. Med. Genet. 1992, 42, 68-84. [CrossRef]

12. Natale, V. A comprehensive description of the severity groups in Cockayne syndrome. Am. J. Med. Genet. Part A 2011, 155a, 1081-1095. [CrossRef]

13. Bloch-Zupan, A.; Rousseaux, M.; Laugel, V.; Schmittbuhl, M.; Mathis, R.; Desforges, E.; Koob, M.; Zaloszyc, A.; Dollfus, H.; Laugel, V. A possible cranio-oro-facial phenotype in Cockayne syndrome. Orphanet J. Rare Dis. 2013, 8, 9. [CrossRef]

14. Tiwari, V.; Baptiste, B.A.; Okur, M.N.; Bohr, V.A. Current and emerging roles of Cockayne syndrome group B (CSB) protein. Nucleic Acids Res. 2021, 49, 2418-2434. [CrossRef]

15. Kou, Y.; Shboul, M.; Wang, Z.; Shersheer, Q.; Lyu, Z.; Liu, P.; Zhao, X.; Tian, J. Novel frame shift mutation in ERCC6 leads to a severe form of Cockayne syndrome with postnatal growth failure and early death: A case report and brief literature review. Medicine 2018, 97, e11636. [CrossRef]

16. Tinsa, F.; Bellalah, M.; Brini, I.; Bousnina, D.; Lehmann, A.; Boussetta, K.; Bousnina, S. Infantile onset of Cockayne syndrome without photosensitivity in a Tunisian girl. La Tunis. Med. 2009, 87, 877-879.

17. Vessoni, A.T.; Guerra, C.C.C.; Kajitani, G.S.; Nascimento, L.L.S.; Garcia, C.C.M. Cockayne Syndrome: The many challenges and approaches to understand a multifaceted disease. Genet. Mol. Biol. 2020, 43, e20190085. [CrossRef] [PubMed]

18. Calmels, N.; Greff, G.; Obringer, C.; Kempf, N.; Gasnier, C.; Tarabeux, J.; Miguet, M.; Baujat, G.; Bessis, D.; Bretones, P.; et al. Uncommon nucleotide excision repair phenotypes revealed by targeted high-throughput sequencing. Orphanet J. Rare Dis. 2016, 11, 26. [CrossRef] [PubMed]

19. Khayat, M.; Hardouf, H.; Zlotogora, J.; Shalev, S.A. High carriers frequency of an apparently ancient founder mutation p.Tyr322X in the ERCC8 gene responsible for Cockayne syndrome among Christian Arabs in Northern Israel. Am. J. Med. Genet. Part A 2010, 152a, 3091-3094. [CrossRef] [PubMed]

20. Ben Chehida, A.; Ghali, N.; Ben Abdelaziz, R.; Ben Moussa, F.; Tebib, N. Renal Involvement in 2 Siblings With Cockayne Syndrome. Iran. J. Kidney Dis. 2017, 11, 253-255.

21. Blin-Rochemaure, N.; Allani-Essid, N.; Carlier, R.; Laugel, V.; Quijano-Roy, S. Place de la neuropathie dans le diagnostic précoce du syndrome de Cockayne: À propos de deux cas dans une fratrie. Arch. Pédiatrie 2017, 24, 353-359. [CrossRef] [PubMed]

22. Kaissi, A.; Safi, H.; Ghachem, M.; Hendaoui, L.; Chehida, F. Congenital dysplastic hips, spinal column abnormalities, fractures and progressive neurological manifestations in Tunisian family with cockayne syndrome. Ann. Afr. Med. $2005,4,83-87$.

23. Geoffroy, V.; Pizot, C.; Redin, C.; Piton, A.; Vasli, N.; Stoetzel, C.; Blavier, A.; Laporte, J.; Muller, J. VaRank: A simple and powerful tool for ranking genetic variants. PeerJ 2015, 3, e796. [CrossRef] [PubMed]

24. Backenroth, D.; Homsy, J.; Murillo, L.R.; Glessner, J.; Lin, E.; Brueckner, M.; Lifton, R.; Goldmuntz, E.; Chung, W.K.; Shen, Y. CANOES: Detecting rare copy number variants from whole exome sequencing data. Nucleic Acids Res. 2014, 42, e97. [CrossRef]

25. Geoffroy, V.; Herenger, Y.; Kress, A.; Stoetzel, C.; Piton, A.; Dollfus, H.; Muller, J. AnnotSV: An integrated tool for structural variations annotation. Bioinformatics 2018, 34, 3572-3574. [CrossRef]

26. Nakazawa, Y.; Yamashita, S.; Lehmann, A.R.; Ogi, T. A semi-automated non-radioactive system for measuring recovery of RNA synthesis and unscheduled DNA synthesis using ethynyluracil derivatives. DNA Repair 2010, 9, 506-516. [CrossRef] 
27. Jia, N.; Nakazawa, Y.; Guo, C.; Shimada, M.; Sethi, M.; Takahashi, Y.; Ueda, H.; Nagayama, Y.; Ogi, T. A rapid, comprehensive system for assaying DNA repair activity and cytotoxic effects of DNA-damaging reagents. Nat. Protoc. 2015, 10, 12-24. [CrossRef] [PubMed]

28. Le May, N.; Calmels, N.; Abiayad, Y.; Boukli, L.; Semer, M.; Serradj, A.; Egly, J.-M.; Laugel, L. Xeroderma pigmentosum groups C and A in Algerian patients with deregulation of both transcription and DNA repair. J. Case Rep. Stud. 2018, 6. [CrossRef]

29. Gitiaux, C.; Blin-Rochemaure, N.; Hully, M.; Echaniz-Laguna, A.; Calmels, N.; Bahi-Buisson, N.; Desguerre, I.; Dabaj, I.; Wehbi, S.; Quijano-Roy, S.; et al. Progressive demyelinating neuropathy correlates with clinical severity in Cockayne syndrome. Clin. Neurophysiol. Off. J. Int. Fed. Clin. Neurophysiol. 2015, 126, 1435-1439. [CrossRef]

30. Newman, J.C.; Bailey, A.D.; Fan, H.Y.; Pavelitz, T.; Weiner, A.M. An abundant evolutionarily conserved CSB-PiggyBac fusion protein expressed in Cockayne syndrome. PLoS Genet. 2008, 4, e1000031. [CrossRef]

31. Karikkineth, A.C.; Scheibye-Knudsen, M.; Fivenson, E.; Croteau, D.L.; Bohr, V.A. Cockayne syndrome: Clinical features, model systems and pathways. Ageing Res. Rev. 2017, 33, 3-17. [CrossRef]

32. Ben Halim, N.; Ben Alaya Bouafif, N.; Romdhane, L.; Kefi Ben Atig, R.; Chouchane, I.; Bouyacoub, Y.; Arfa, I.; Cherif, W.; Nouira, S.; Talmoudi, F.; et al. Consanguinity, endogamy, and genetic disorders in Tunisia. J. Community Genet. 2013, 4, $273-284$. [CrossRef]

33. Romdhane, L.; Mezzi, N.; Hamdi, Y.; El-Kamah, G.; Barakat, A.; Abdelhak, S. Consanguinity and Inbreeding in Health and Disease in North African Populations. Annu. Rev. Genom. Hum. Genet. 2019, 20, 155-179. [CrossRef]

34. Lake, R.J.; Fan, H.Y. Structure, function and regulation of CSB: A multi-talented gymnast. Mech. Ageing Dev. 2013, 134, $202-211$. [CrossRef] [PubMed]

35. Frontini, M.; Proietti-De-Santis, L. Interaction between the Cockayne syndrome B and p53 proteins: Implications for aging. Aging 2012, 4, 89-97. [CrossRef] [PubMed]

36. Okur, M.N.; Lee, J.H.; Osmani, W.; Kimura, R.; Demarest, T.G.; Croteau, D.L.; Bohr, V.A. Cockayne syndrome group A and B proteins function in rRNA transcription through nucleolin regulation. Nucleic Acids Res. 2020, 48, 2473-2485. [CrossRef]

37. Paccosi, E.; Costanzo, F.; Costantino, M.; Balzerano, A.; Monteonofrio, L.; Soddu, S.; Prantera, G.; Brancorsini, S.; Egly, J.M.; Proietti-De-Santis, L. The Cockayne syndrome group A and B proteins are part of a ubiquitin-proteasome degradation complex regulating cell division. Proc. Natl. Acad. Sci. USA 2020, 117, 30498-30508. [CrossRef] [PubMed]

38. Aamann, M.D.; Sorensen, M.M.; Hvitby, C.; Berquist, B.R.; Muftuoglu, M.; Tian, J.; de Souza-Pinto, N.C.; Scheibye-Knudsen, M.; Wilson, D.M., 3rd; Stevnsner, T.; et al. Cockayne syndrome group B protein promotes mitochondrial DNA stability by supporting the DNA repair association with the mitochondrial membrane. FASEBJ. Off. Publ. Fed. Am. Soc. Exp. Biol. 2010, 24, $2334-2346$. [CrossRef]

39. Epanchintsev, A.; Costanzo, F.; Rauschendorf, M.A.; Caputo, M.; Ye, T.; Donnio, L.M.; Proietti-de-Santis, L.; Coin, F.; Laugel, V.; Egly, J.M. Cockayne's Syndrome A and B Proteins Regulate Transcription Arrest after Genotoxic Stress by Promoting ATF3 Degradation. Mol. Cell 2017, 68, 1054-1066.e6. [CrossRef] [PubMed]

40. Epanchintsev, A.; Rauschendorf, M.-A.; Costanzo, F.; Calmels, N.; Obringer, C.; Sarasin, A.; Coin, F.; Laugel, V.; Egly, J.-M. Defective transcription of ATF3 responsive genes, a marker for Cockayne Syndrome. Sci. Rep. 2020, 10, 1105. [CrossRef]

41. Crochemore, C.; Fernández-Molina, C.; Montagne, B.; Salles, A.; Ricchetti, M. CSB promoter downregulation via histone H3 hypoacetylation is an early determinant of replicative senescence. Nat. Commun. 2019, 10, 5576. [CrossRef]

42. Cleaver, J.E.; Hefner, E.; Laposa, R.R.; Karentz, D.; Marti, T. Cockayne syndrome exhibits dysregulation of p21 and other gene products that may be independent of transcription-coupled repair. Neuroscience 2007, 145, 1300-1308. [CrossRef] [PubMed]

43. Citterio, E.; Van Den Boom, V.; Schnitzler, G.; Kanaar, R.; Bonte, E.; Kingston, R.E.; Hoeijmakers, J.H.; Vermeulen, W. ATPdependent chromatin remodeling by the Cockayne syndrome B DNA repair-transcription-coupling factor. Mol. Cell. Biol. 2000, 20, 7643-7653. [CrossRef] [PubMed]

44. Le May, N.; Mota-Fernandes, D.; Vélez-Cruz, R.; Iltis, I.; Biard, D.; Egly, J.M. NER factors are recruited to active promoters and facilitate chromatin modification for transcription in the absence of exogenous genotoxic attack. Mol. Cell 2010, 38, 54-66. [CrossRef]

45. Wang, L.; Limbo, O.; Fei, J.; Chen, L.; Kim, B.; Luo, J.; Chong, J.; Conaway, R.C.; Conaway, J.W.; Ranish, J.A.; et al. Regulation of the Rhp26ERCC6/CSB chromatin remodeler by a novel conserved leucine latch motif. Proc. Natl. Acad. Sci. USA 2014, 111, 18566-18571. [CrossRef] [PubMed]

46. Sin, Y.; Tanaka, K.; Saijo, M. The C-terminal Region and SUMOylation of Cockayne Syndrome Group B Protein Play Critical Roles in Transcription-coupled Nucleotide Excision Repair. J. Biol. Chem. 2016, 291, 1387-1397. [CrossRef]

47. Sonmez, F.M.; Celep, F.; Ugur, S.A. Severe Form of Cockayne Syndrome With Varying Clinical Presentation and No Photosensitivity in a Family. J. Child Neurol. 2006, 21, 333-337. [CrossRef]

48. Colella, S.; Nardo, T.; Mallery, D.; Borrone, C.; Ricci, R.; Ruffa, G.; Lehmann, A.R.; Stefanini, M. Alterations in the CSB gene in three Italian patients with the severe form of Cockayne syndrome (CS) but without clinical photosensitivity. Hum. Mol. Genet. 1999, 8, 935-941. [CrossRef]

49. Balogun, S.A.; Balogun, R.A.; Evans, J. Age-related differences in renal function at onset of renal replacement therapy in chronic kidney disease stage 5 patients. QJM Mon. J. Assoc. Physicians 2006, 99, 595-599. [CrossRef]

50. Chatre, L.; Biard, D.S.F.; Sarasin, A.; Ricchetti, M. Reversal of mitochondrial defects with CSB-dependent serine protease inhibitors in patient cells of the progeroid Cockayne syndrome. Proc. Natl. Acad. Sci. USA 2015, 112, E2910-E2919. [CrossRef] 